\title{
Editorial
}

\section{New Processes and Machine Tools for Advanced Metal Alloys}

\author{
Luis Norberto López de Lacalle ${ }^{1, *(1)}$ and Ainhoa Celaya ${ }^{2, *}$
}

1 Centre of Advanced Manufacturing Technologies for Aeronautics CFAA, Department of Mechanical Engineering, University of the Basque Country (UPV/EHU), Parque Tecnológico de Zamudio 202, 48170 Bilbao, Spain

2 Department of Mechanical Engineering (High Performance Manufacturing Group), University of the Basque Country (UPV/EHU), EIB, Plaza Ingeniero Torres Quevedo, 1, 48013 Bilbao, Spain

* Correspondence: norberto.lzlacalle@ehu.eus (L.N.L.d.L.); ainhoa.celaya@ehu.eus (A.C.)

Received: 5 February 2020; Accepted: 5 February 2020; Published: 6 February 2020

Advanced materials are crucial for the development of many industrial sectors such as aerospace, automotive, energy, among others. These materials show superior mechanical characteristics of strength, hardness, toughness, and durability in comparison to conventional materials. However, these materials are also characterized by their complicated primary processes (e.g., casting or forge) and the secondary processes (e.g., machining) because of their low machinability.

In addition, the development of new advanced materials requires the use of advanced manufacturing technologies supported on new and high-quality machine tools. In this decade, machine tools are becoming multitasking systems, that is, a combination of milling centers, lathes, and even grinding machines. Thanks to computer numerical control (CNC), users are able to interpolate and synchronize several machine axes, as well as find new mechanical solutions for transmissions based on direct hollow motors, or linear guided ones, including lineal motors. Machine tools are particularly stiff spatial manipulators, in order to achieve tolerances reaching an order of magnitude in the hundredths.

New processes and new cooling systems, tools, and coatings must be investigated to enable the machining of these advanced materials. Machines that apply the processes can be also improved by introducing new components, control approaches, and monitoring and recording systems. The concept of digitalization in the global industry 4.0 is now a hot topic, including the use of artificial intelligence utilities [1].

This Special Issue includes works that present new forming and machining processes used on special steels and titanium alloys, define machine precision using a new metrology approach, and give some ideas about how to improve machinability by adding small amounts of chemical elements to steels.

It is difficult to propose an up-to-date classification of machine tools, a task made even more difficult after the introduction of additive manufacturing in workshops. Table 1 proposes a new classification, based on a previous one given in [2]. 
Table 1. Current classification of machine tools.

Defined cutting edge (cutting)

Main motion: translation

- $\quad$ Broaching machine

- $\quad$ Bandsaw and hacksaw

- $\quad$ Planer and shaper

- $\quad$ Slotting machine

Main motion: rotation

- Turning:

Engine universal lathe

Vertical lathe (vertical boring mill)

Drum turret lathe

Multi-spindle lathe

- Milling:

$\bigcirc \quad$ Universal knee milling machine

$\bigcirc \quad$ Vertical milling machine

- Boring:

$\bigcirc \quad$ Horizontal

- Drilling:

Bench drill

Drill press (upright drill press)

Radial drill press

Multi-spindle drill

Drum turret drill

Deep drilling machine

- Sawing:

Circular or disk sawing machines (cold saws)

Machining center: Machine designed to use rotating tools, with the capability of milling, drilling, boring, and tapping:

- Vertical

- Horizontal

Five-axis milling machines: Five-axis machines allow very complex part machining

Turning center: Machine derived from a lathe with the capability of turning and milling, including:

- $\quad$ Motorized tools in a drum turret

- $\quad$ Milling headstock

Transfer machines and systems

Non-conventional (erosion)

- Electro-discharge machining:

Wire (WEDM)

S Sinking (SEDM)

- $\quad$ Electrochemical machining (ECM)
- $\quad$ Electron beam machining (EBM)

- Ultrasonic machining (USM)

Gear manufacturing machines

Undefined cutting edge (abrasive)

- Grinding:

Cylindrical grinder:

- $\quad$ External

- Internal

- Surface grinder:

- $\quad$ Rotating

- $\quad$ Reciprocating

- $\quad$ Creep grinding

Point grinder

Centerless grinder

Tool grinder

- Honing:

$\begin{array}{ll}\bigcirc & \text { Short stroke } \\ & \text { Long stroke }\end{array}$

- Lapping:

Single side

Double side

- $\quad$ True friction sawing machines (disk and band)

- $\quad$ Abrasive disk sawing machines

Laser: Lasers can be used for cutting metal sheets, welding, material deposition, and material ablation Multitask machine: Machine that combines two machining processes:

- $\quad$ Milling and turning

- $\quad$ Turning and grinding

- $\quad$ Milling and grinding

Hybrid machine: Machine combining a machining process and other processes

LMD (laser metal deposition) stations: Machines that use a laser to melt metal powder on the focal point, building up pieces by the nozzle movement, making weld beads

WAAM: Wire and arc additive manufacturing stations Metal 3D printers: Usually use powder bed technology, building up pieces layer by layer

Conflicts of Interest: The authors declare no conflict of interest. 


\section{References}

1. Arnaiz-González, A.; Fernández-Valdivielso, A.; Bustillo, A.; Lopez de Lacalle, L.N. Using artificial neural networks for the prediction of dimensional error on inclined surfaces manufactured by ball-end milling. Int. J. Adv. Manuf. Technol. 2016, 83, 847-859. [CrossRef]

2. López de Lacalle, L.N.; Lamikiz, A. Machine Tools for High Performance Machining; Springerg: Berlin, Germany, 2009. 